\title{
Experimental mitral valve replacement with a heterograft aortic valve in a rigid metal ring
}

\author{
E. P R OCT O R
}

\author{
From the Thoracic Research Department, Guy's Hospital, London S.E.I
}

\begin{abstract}
A mitral valve replacement is described in which a heterograft (pig) aortic valve is supported in a rigid metal ring having three spurs to support the commissures. The ring frame is completely covered by the heterograft, and no artificial material is in contact with the blood stream. Completely fabricated and tested for competency beforehand, it requires only one row of interrupted sutures-after the manner of the Starr-Edwards prosthesis-for insertion, and can be used in either the mitral or the aortic position. Experimental results in the dog indicate that the valve may require only temporary anticoagulation to cover the immediate post-operative period.
\end{abstract}

The success, in suitable cases, of the homograft aortic valve placed in the sub-coronary position (Ross, 1962, 1963, 1964, 1967 ; Barratt-Boyes, 1964, 1965) and the problems associated with metal and plastic prostheses (Björk and Malers, 1964 ; Hughes, 1965 ; Kloster, Bristow, and Griswold, 1965) have prompted much research towards replacing the diseased mitral valve with a homograft mitral valve. This has proved more difficult than aortic valve replacement. The problem is mainly related to difficulties of insertion and matching of chordal and annulus dimensions both acutely, in anticipation of a subsequent change of dimensions post-bypass, and in the long run, as the left ventricle becomes smaller after successful correction. This problem is lessened in the experimental animal, where the normal valve can be matched or a larger valve used, but, in spite of this, the results of mitral homograft replacement in animals are not good (Hubka, Siska, and Holec, 1967 ; Pappas, Titus, Berghuis, McKenzie, and Ellis, 1966). Replacement with 'mitral valves' fashioned from autologous fascia lata accurately matched for size is no better (Flege, Rossi, Auer, and Ehrenhaft, 1967).

Another approach, which avoids the problems associated with chordal dimensions and ventricular fixation, is to use semi-lunar valves. Experimentally, the mitral valve has been replaced with an autologous pulmonary valve (Lower, Stofer, and Shumway, 1961) and with a homologous pulmonary valve (Lower and Shumway, 1963), but more recently the homograft aortic valve has been preferred. McKenzie, Titus, Rastelli, Pappas, and
Ellis (1966) replaced the mitral valve in dogs by suturing the base of the aortic homograft to the mitral annulus and anchoring the commissures, reinforced with Teflon, to the left ventricular myocardium at three sites. They later rejected the technique as unsatisfactory due to the development of stenosis in the region of the mitral annulus associated with contraction at the base of the valve ; the cusps remained pliable, mobile, and only slightly thickened up to one year after insertion. Hubka, Šska, and Holec (1967) avoided the problems associated with ventricular fixation by placing the homograft aortic valve in the left atrium immediately above the mitral annulus, with the commissures attached to the annulus and the base of the valve sutured to the left atrial wall ; it remains to be seen whether stenosis will result.

The difference in flow cross-sections of the aortic and mitral valves usually means that a homograft aortic valve in the mitral region is likely to cause a relative obstruction. The larger sizes of valve obtainable as heterografts are therefore more suitable if maximal flow is required. In an effort to develop a mitral valve replacement devoid of the disadvantages outlined above, we have, in the dog, over the last two years been using heterograft (pig) aortic valves supported in a metal ring. Recently, Ionescu, Wooler, Smith, and Grimshaw (1967) have published impressive clinical results of mitral valve replacement with pig aortic valves supported in a semi-rigid Teflon ring. We are much encouraged by this confirmation of the value of the supported heterograft aortic valve in the mitral position. 
There is, however, still room for improvement, and we submit another method of using the heterograft valve in the mitral region.

\section{METHOD}

The experiments were carried out on 28 dogs (22$30 \mathrm{~kg}$.). Anaesthesia was maintained with halothane and oxygen. To avoid the problems associated with the use of homologous blood in dogs (Gadboys, Jones, Slonim, Wisoff, and Litwak, 1963), a total haemodilution bypass technique was adopted, using an oxygenator of our own design (Proctor and de Bono, 1965) ; no homologous blood was used either during the bypass or post-operatively. Duration of the bypass was two hours; insertion of the valve required one hour.

PREPaRation of THE VALVE The stainless steel ring (Figs 1 and 2) has been made from a tube of 1.0 in. o.d. EN $58 \mathrm{~J}$ steel of $\frac{1}{16}$ in. thickness. Holes were drilled in the top of the spurs and midway between the spurs. In the majority of the pig valves the noncoronary cusp is appreciably smaller, and the sizes and angles of the spurs are shown in Figure 1. In the 22-30 kg. dogs the ring size suitable for the mitral annulus was $2.5 \mathrm{~cm}$., but, maintaining the same proportions, rings of $3.2 \mathrm{~cm}$. and $3.4 \mathrm{~cm}$., suitable
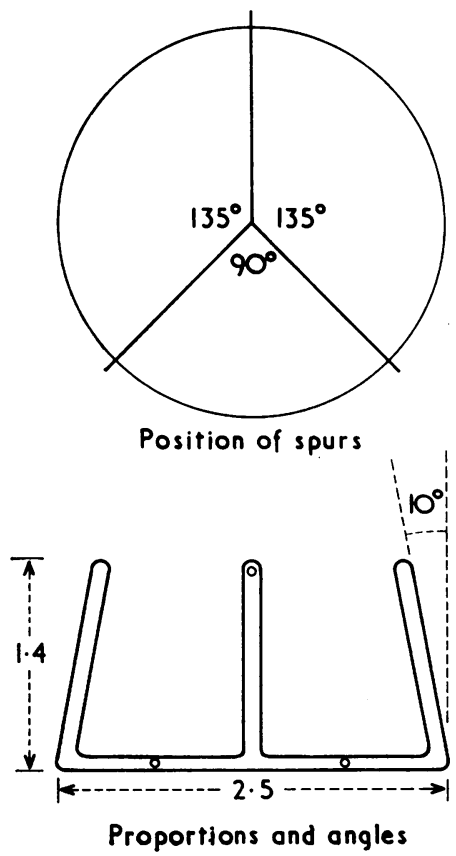

FIG. 1. Diagram of the proportions and angles of the stainless steel ring, showing closer spacing for the noncoronary cusp.

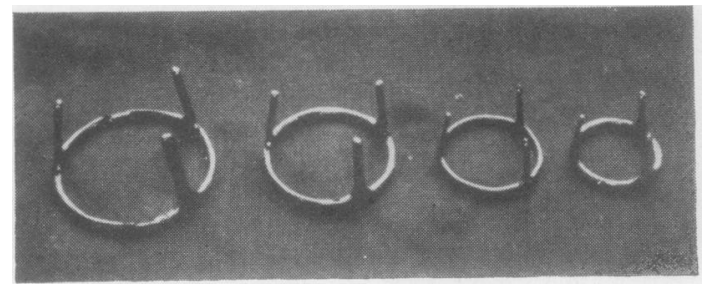

FIG. 2. Series of rings: $3.4 \mathrm{~cm} ., 3.2 \mathrm{~cm} ., 2.9 \mathrm{~cm}$., and $2.5 \mathrm{~cm}$. (latter size used in all dog mitral valve replacements).

for human mitral valve sizes, can be made from tube of $1 \frac{1}{4}$ and $1 \frac{3}{8}$ in. o.d. After polishing, the spurs were bent inwards by $10^{\circ}$; this permits better matching of valve and ring and facilitates insertion. Suture material for attaching the valve to the ring was 5-0 silk for the $2.5 \mathrm{~cm}$. size and 4-0 for the larger sizes. A series of ring sizes of $3 \cdot 4,3 \cdot 2,2 \cdot 9$, and $2 \cdot 5 \mathrm{~cm}$. are shown in Figure 2.

The $2.5 \mathrm{~cm}$. diameter aortic valves were dissected from pig hearts weighing $450-500 \mathrm{~g}$. The hearts were collected unsterile from the market as frozen specimens. The valve was dissected from the heart over the next few hours. To prevent further contamination dissection was carried out in a solution of $1 / 1,000$ chlorhexidine. The sequence of the preparation of the valve is shown diagrammatically in Fig. 3 and an actual specimen in Figure 4. A rim of aortic wall, $2 \mathrm{~mm}$. wide, was left above the cusps, and a skirt of tissue, 7-8 $\mathrm{mm}$. wide, was left below the cusps. The coronary artery used for covering the spurs was obtained by dissecting out the proximal $5-6 \mathrm{~cm}$. of the right coronary artery before removing the valve. Most of the fat and adventitia was removed, and 15-20 $\mathrm{mm}$. sections were selected. These were split for two-thirds of their length, one end being closed with a continuous suture, and then everted.

VALVE TESTING During preparation the valve was tested for regurgitation at the stage where the skirt was folded over the ring and sutured. This was done by holding the valve, in a sleeve, against a head of pressure of $200 \mathrm{~mm}$. Hg, using a reservoir of $1 / 1,000$ chlorhexidine. At this stage most of the valves were liquid-tight, but occasionally a small amount of regurgitation was observed. If this was due to the valve being too large or too small, it was discarded; if due to a fault in suturing, this was corrected. The valve was again tested for regurgitation after the spurs had been covered with coronary artery.

It should be noted that the creation of a competent valve was a thing of leisure in vitro, not of haste during the bypass.

STERILIZATION AND FREEZE-DRYING Sterilization was carried out by incubating the valve at $37^{\circ} \mathrm{C}$. for two hours in a $1 \%$ saline solution of beta-propiolactone. 


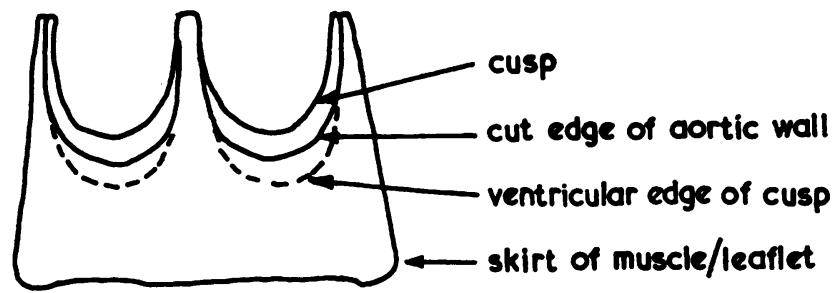

\section{a). Prepared valve}
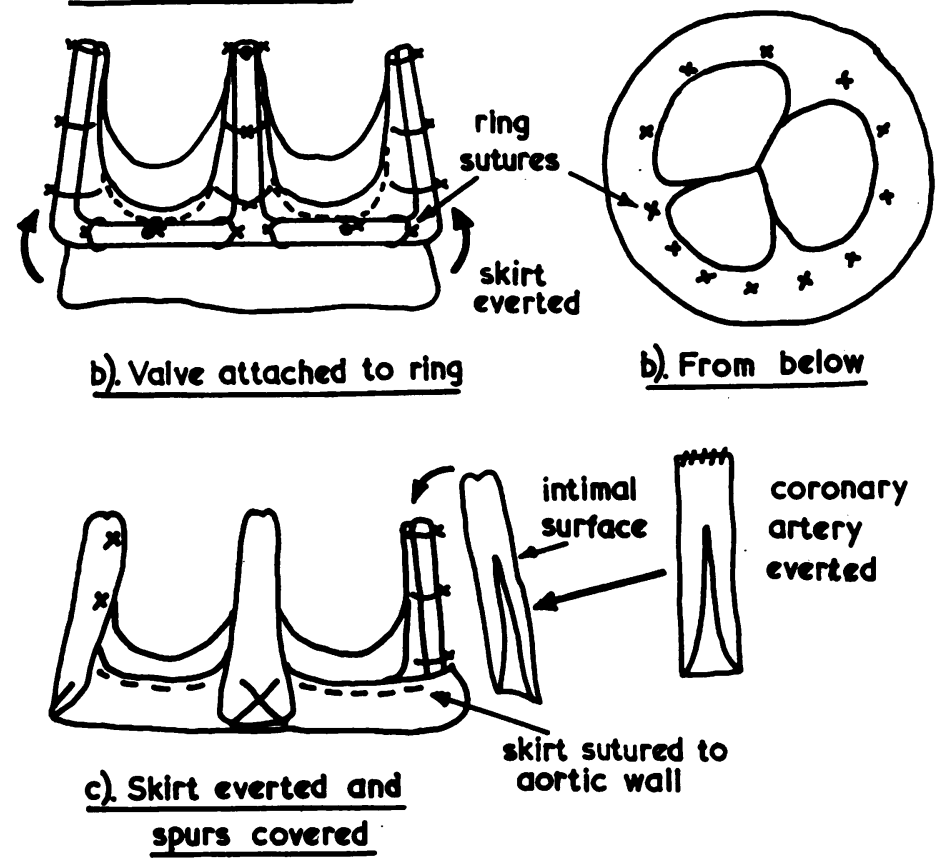

FIG. 3. Diagram of the sequence of preparation of the supported valve.

The valve was then rinsed several times with sterile distilled water to remove any saline off the surface, frozen at $-80^{\circ} \mathrm{C}$., and then freeze-dried for 48 hours. A bank specimen is shown in Figure 4c.

INSERTION OF THE VALVE The valve was reconstituted in saline 20-30 minutes before use. During this period the mitral valve was removed, except for a 3-4 mm. rim of leaflet. Four quadrant, marker sutures of 2-0 Mersilene were placed around this rim (Fig. 5), and three 2-0 Mersilene sutures were inserted between each marker suture-16 in all. The reconstituted valve was then attached to the underside of the valve holder with three temporary ties. This allowed the valve to be manipulated and sutured without damage to the friable tissue. The ring was orientated so that one of the wider cusps $\left(135^{\circ}\right)$ was opposite the recipient aortic valve. The four quadrant sutures were then inserted in the valve, care being taken to pass the needle between the ring and the cusps (Fig. 5 inset); the remaining sutures were then placed between them. When all the sutures were through the valve base the temporary ties were cut and the valve holder was removed. The valve was then ready for sliding down the sutures into the annulus (Fig. 6). During the period when the valve was on the holder it was frequently moistened to prevent drying of the tissue. The next stage, that of sliding the valve down the sutures, was the most critical part of the insertion, as great care had to be taken to ensure that the spurs did not entangle with the adjacent sutures. This was prevented by slipping a polythene guard or 'shoehorn' over the spur and between the two adjacent sutures (Fig. 7) when the valve was $2-3 \mathrm{~cm}$. from the annulus. This was done first with the bottom spur and then with the more accessible top spurs. The correct position of the valve was on top of the recipient mitral leaflet (Fig. 8). When the valve was in place the sutures were tied, beginning with the bottom sutures. After tying down, the valve was 


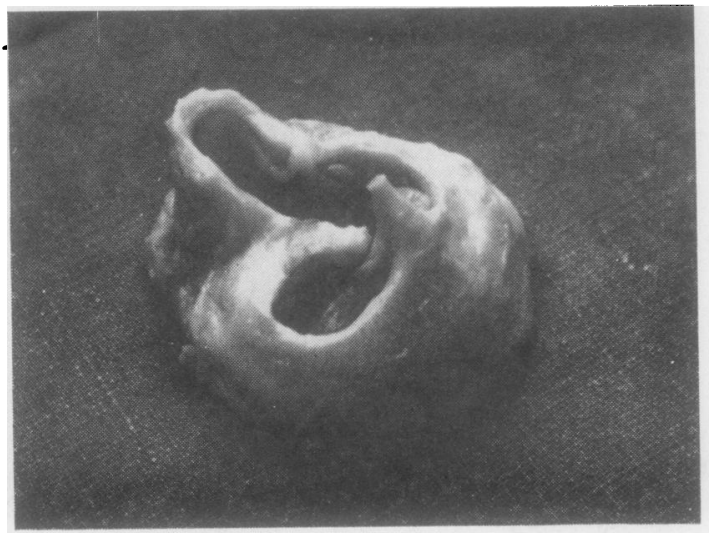

(a)

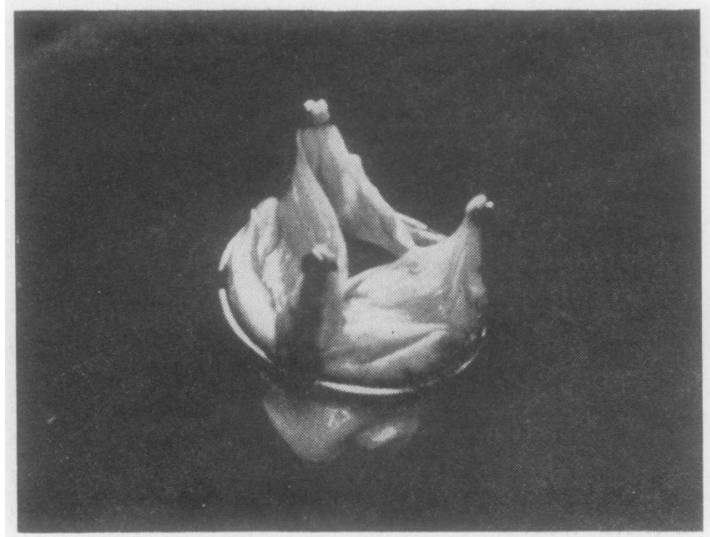

(b)

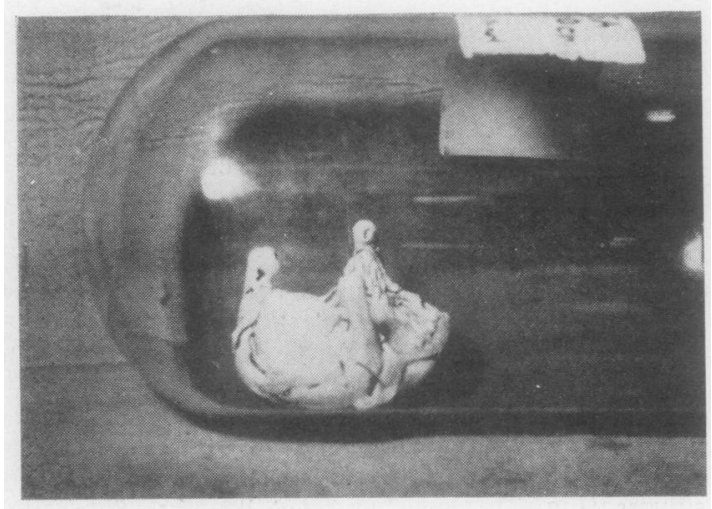

(c)

FIG. 4. Appearance of valve at the three main stages in preparation: (a) dissected out; (b) sutured to ring-skirt ready for eversion; (c) valve completed, with skirt everted and spurs covered with coronary artery. Bank specimen. tested for regurgitation, either by filling the left ventricle with saline and squeezing it ; tripping the aortic valve ; or connecting the left ventricular vent to the pump arterial line, with suitable provision for the prevention of air embolism. With a properly inserted valve this should not really be necessary, since the competency of the valve depends upon the ring, which cannot be distorted by the insertion. Figure 9 shows the left atrial and left ventricular views of a valve in a dog dispatched in good health at 72 hours.

The chest drains were removed 20-24 hours after insertion, and at 30 hours temporary anticoagulation was begun with intramuscular heparin, 8,000 units b.d. Prophylactic antibiotics were given over the same period.

\section{RESULTS}

When the heart was defibrillated and the bypass discontinued, the valve was found to be competent in all 28 dogs. Mean left atrial pressures, measured with an open saline manometer, were in the range $6-12 \mathrm{~cm} . \mathrm{H}_{2} \mathrm{O}$. Systemic arterial pressures were in the pre-bypass range of 100-120 $\mathrm{mm}$. $\mathrm{Hg}$ (mean), and the venous pressures were in the range $2-6 \mathrm{~cm} . \mathrm{H}_{2} \mathrm{O}$. All the dogs survived the operation, but 12 died 18-36 hours postoperatively. These were mainly in the early part of the series, and the cause of death was predominantly haemorrhage in eight dogs; no obvious cause was found in the other four. The valve was never directly the cause of death ; there was no evidence at any time of malfunction, and the valve was still competent at necropsy when re-tested in situ. A further six dogs died in the period $1 \frac{1}{2}-7$ days from clotting originating on the left atrial suture line; the cusps were unaffected. The dog has a much greater tendency to clot on intra-cardiac sutures and prostheses than man, particularly in the left atrium. If the dog survived this early period the valve 'settled in' and anticoagulation could be stopped. Nine dogs died in the period 8-32 days from cusp damage due to bacterial endocarditis, in spite of antibiotics. This high incidence of infection is one of the main difficulties with this otherwise useful experimental animal, and occurs just as often with homografts (McKenzie et al., 1966) and autografts (Flege et al., 1967). One dog is alive and extremely active at 10 weeks, the latter eight weeks without anticoagulants or antibiotics.

\section{DISCUSSION}

Although a less attractive concept than the mitral homograft, the supported aortic heterograft has a number of significant advantages: 


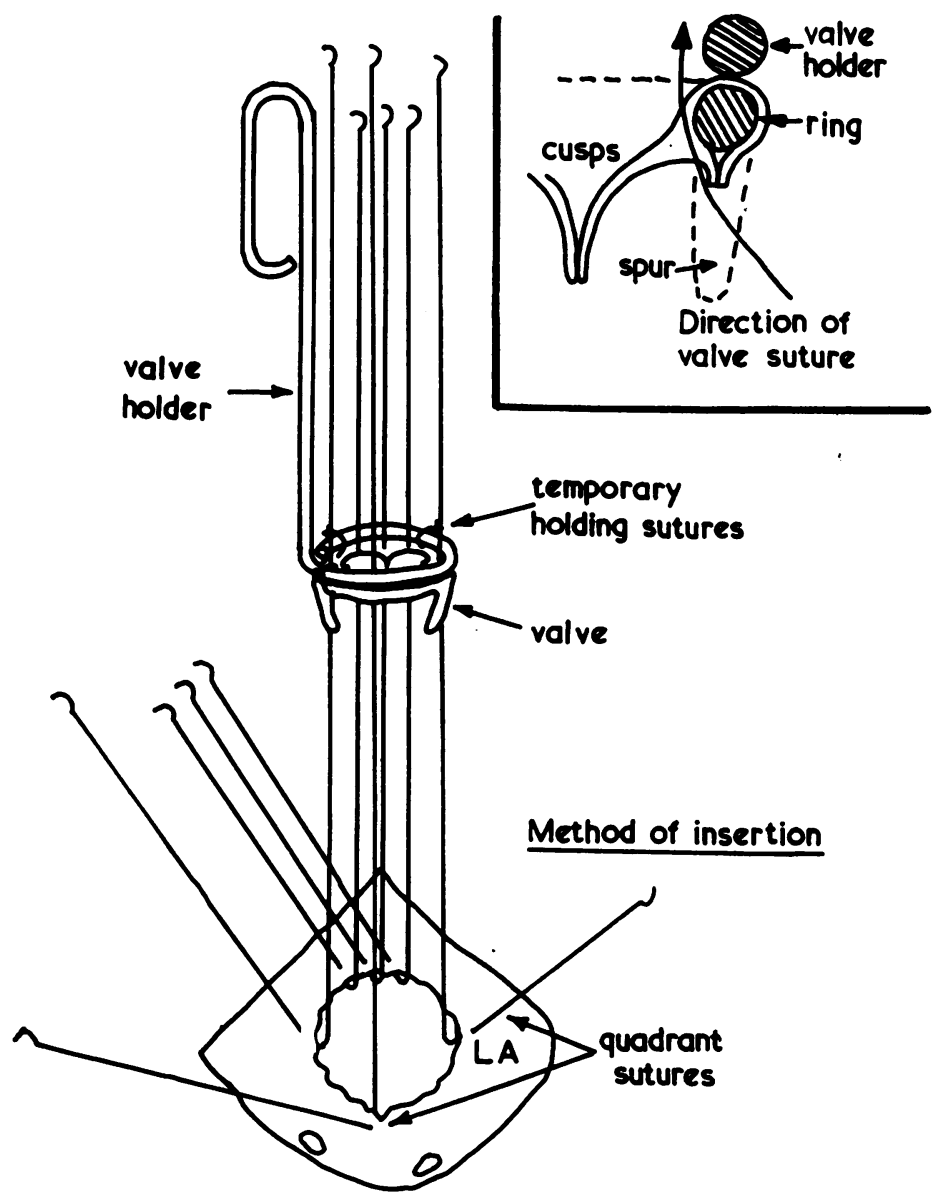

FIG. 5. Valve on valve holder. Technique of suturing valve.

FIG. 6. Valve holder removed and valve ready for insertion. 


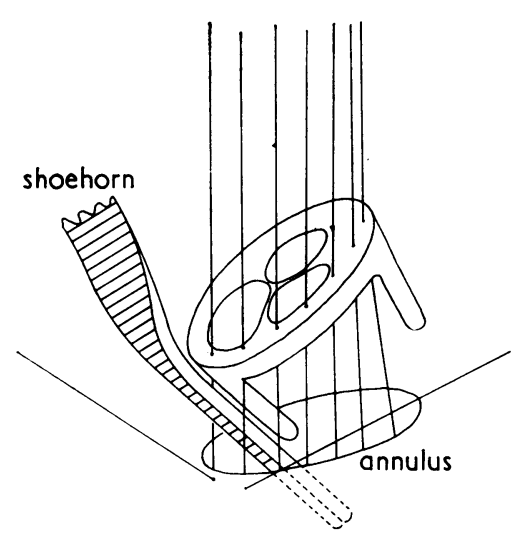

FIG. 7. Technique of insertion to prevent spurs entangling adjacent sutures.

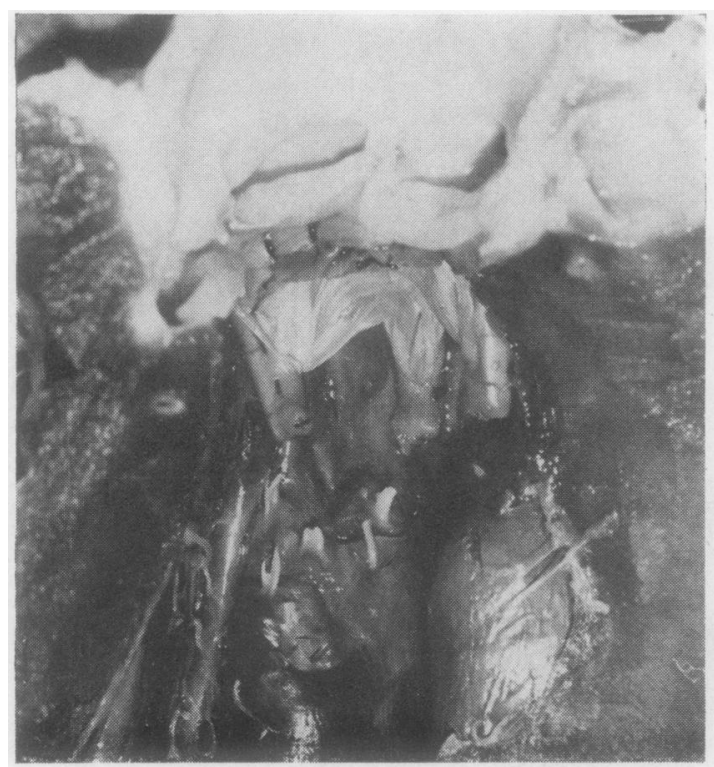

(a)

FIG. 9. Specimen from dog dispatched at 72 hours. to recipient aortic valve. (b) View from left atrium.

1. It requires no ventricular attachment, and is therefore free from the technical problems associated with this method.

2. An unlimited number of grafts are available in all the required sizes; furthermore, they are from young, healthy animals. This uniformity of graft material is likely to become still more important in the next phase of work on tissue

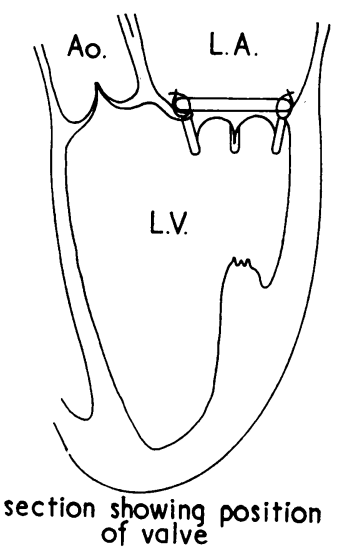

FIG. 8. Correct position of valve on top of annulus after tying down.

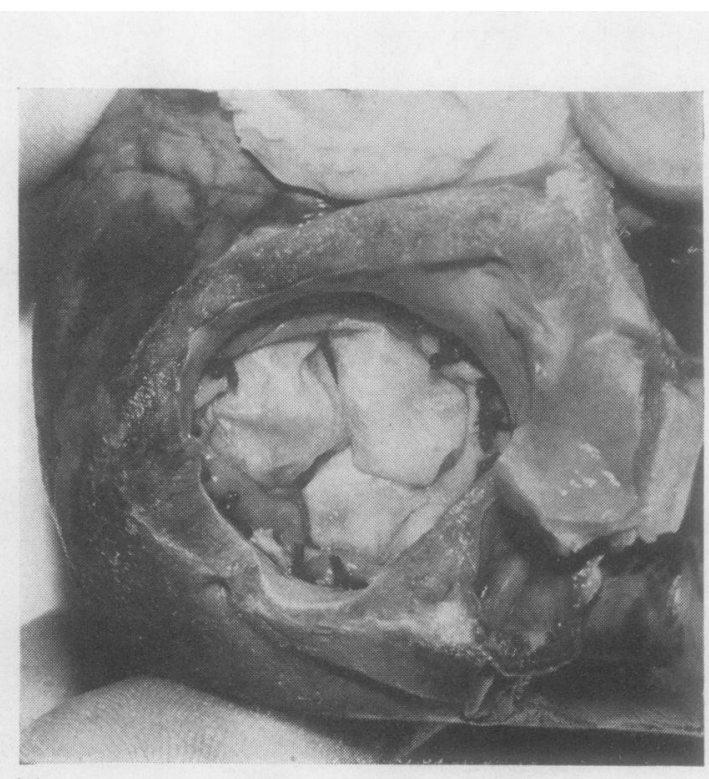

(b)

(a) View from left ventricle showing larger cusp adjacent valves, which will be concerned, by improvements in preparation, sterilizing, and storage, with extending the useful life of these valves. To attempt this with the heterogeneous material used as homografts is statistically unsound.

3. The supported graft is tested for competency in vitro, and a great deal of time is available for establishing competency, in contrast to the limited 
time available during the bypass for corrections.

4. The rigid ring prevents distortion of the valve during insertion, and guarantees-if properly inserted-the architecture of the valve during function.

5. The rigid ring avoids the tendency to fatigue and fracture inherent in a flexible ring.

6. The use of a single row of sutures allows a more rapid insertion-after the manner of the Starr-Edwards prosthesis-where the myocardial function is suspect.

7. Although originally conceived as a mitral valve replacement, the single suture line insertion technique renders it suitable for aortic valve replacement in those cases where speed of insertion or local suturing difficulties diminish the value of the homograft.

8. Since the ring is completely covered with tissue, and no foreign material such as Teflon or polypropylene fabric is used, it may well be unnecessary to use long-term anticoagulation after the initial settling in period.

Apropos the donor-host reaction to heterograft tissue, there is good evidence of the acceptance of heterograft valves (Duran and Gunning, 1965 ; O'Brien and Clarebrough, 1966). It appears that there is virtually no difference in the response of the host to a homograft or heterograft valve.

I am grateful to Lord Brock for his support and encouragement in this work. I should also like to thank D. Phelan, A. Smith, and G. Matthews for their enthusiastic technical assistance.

This study was supported in part by a grant from the British Heart Foundation.

\section{REFERENCES}

Barratt-Boyes, B. G. (1964). Homograft aortic valve replacement in aortic incompetence and stenosis. Thorax, 19, 131.

(1965). A method for preparing and inserting a homograft aortic valve. Brit. J. Surg., 52, 847.

Björk, V. O., and Malers, E. (1964). Total mitral valve replacement: late result. J. thorac. cardiovasc. Surg., 48,625 .

Duran, C. G., and Gunning, A. J. (1965). Heterologous aortic-valve transplantation in the dog. Lancet, $2,114$.

Flege, J. B., Rossi, N. P., Auer, J. E., and Ehrenhaft, J. L. (1967). Technique of mitral valve replacement with autologous fascia lata. J. thorac. cardiovasc. Surg., 54, 222.

Gadboys, H. L., Jones, A. R., Slonim, R., Wisoff, B. G., and Litwak, R. S. (1963). The homologous blood syndrome. III. Influence of plasma, buffy coat and red cells in provoking its manifestations. Amer. J. Cardiol., 12, 194.

Hubka, M., Sǐska, K., and Holec, V. (1967). Replacement of the mitral valve with an aortic valve homograft implanted into the left atrium. J. thorac. cardiovasc. Surg., 53, 260.

Hughes, R. K. (1965). Complications of Starr-Edwards mitral valve replacement. Ibid., 49, 731 .

Ionescu, M. I., Wooler, G. H., Smith, D. R., and Grimshaw, V. A. (1967). Mitral valve replacement with aortic heterografts in humans. Thorax, 22, 305.

Kloster, F. E., Bristow, J. D., and Griswold, H. E. (1965). Medical problems in mitral and multiple valve replacement. Progr. cardiovasc. Dis., 7,504

Lower, R. R., Stofer, R. C., and Shumway, N. E. (1961). Total excision of the mitral valve and replacement with the autologous pulmonic valve. J. thorac. cardiovasc. Surg., 42, 696.

- and Shumway, N. E. (1963). Replacement of the dog mitral valve with a homograft. Surg. Forum, 14, 247.

McKenzie, M. B., Titus, J. L., Rastelli, G. C., Pappas, G., and Ellis, F. H., Jr. (1966). Replacement of the canine mitral valve with semilunar valves. J. thorac. cardiovasc. Surg., 51, 168.

O'Brien, M. F., and Clarebrough, J. K. (1966). Heterograft aortic valve transplantation for human valve disease. Aust. med. J., 2 , 228.

Pappas, G., Titus, J. L., Berghuis, J., McKenzie, M. B., and Ellis, F. H., Jr. (1966). Dog mitral valve homografts and heterografts. Surg. Forum, 17, 175.

Proctor, E., and de Bono, A. H. (1965). A low priming volume oxygenator for bloodless priming in cardiopulmonary bypass. Thorax, 20, 540.

Ross, D. N. (1962). Homograft replacement of the aortic valve. Lancet, $2,487$.

- (1963). Surgical reconstruction of the aortic valve. Ibid., 1, 571 (1964). Homotransplantation of the aortic valve in the subcoronary position. J. thorac. cardiovasc. Surg., 47, 713.

(1967). Homograft replacement of the aortic valve-technique. Brit. J. Surg., 54, 165. 